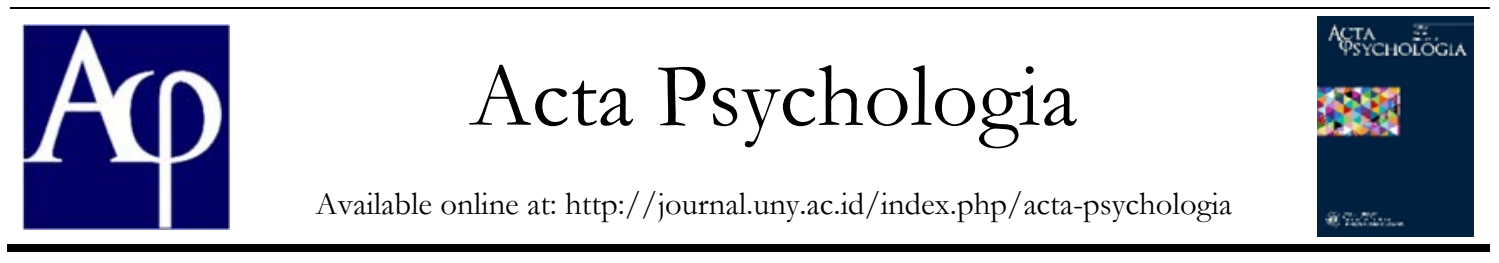

\title{
Hubungan Kualitas Hidup dan Psychological Well-Being pada Anggota Keluarga yang Menjadi Caregiver Pasien Kanker di Kota Bandung
}

\author{
Arinurasti Rabma Lestari, Siti Robmah Nurbayati \\ Jurusan Psikologi, Universitas Negeri Yogyakarta; Jl. Colombo No. 1 Sleman Yogyakarta, 55281 \\ arinurastirahmal@gmail.com
}

\begin{abstract}
Abstrak
Penyakit kanker merupakan penyebab utama kematian di dunia. Dalam banyak kasus, pasien kanker tidak hanya berjuang sendiri untuk penyembuhan, tetapi juga didampingi oleh anggota keluarga yang menjadi caregiver. Ada sebagian caregiver yang kesulitan untuk mewujudkan kualitas hidup dan psychological well-being yang baik. Oleh karena itu, penelitian ini bertujuan untuk mengetahui keadaan dan hubungan antara kualitas hidup dengan psychological wellbeing pada anggota keluarga yang menjadi caregiver pasien kanker. Penelitian ini menggunakan pendekatan kuantitatif dengan jenis penelitian korelasional. Penelitian dilakukan di Rumah Singgah Sehat Sejahtera dan Rumah Singgah Kasih yang berada di kota Bandung. Subjek penelitian berjumlah 112 orang dengan menggunakan teknik pengambilan sampel accidental sampling. Alat pegumpulan data menggunakan Skala Kualitas Hidup dan Skala Psychological Well-being. Reliabilitas dalam skala penelitian ini menggunakan koefisien reliabilitas Alpha Cronbach sebesar 0,893 $(\alpha=0,893)$ pada skala kualitas hidup dan $0,938(\alpha=0,938)$ pada sekala psychological well-being. Data dalam penelitian ini dianalisis menggunakan teknik korelasi product moment dari Pearson. Koefisien korelasi yang diperoleh sebesar 0,619 dengan probabilitas 0,000 ( $p<0,01)$. Hasil penelitian menunjukkan bahwa kualitas hidup dan psychological well-being memiliki hubungan yang positif. Hal ini berarti semakin tinggi tingkat kualitas hidup caregiver maka tingkat psychological wellbeing akan semakin tinggi.
\end{abstract}

Kata Kunci: kualitas hidup, psychological well-being, caregiver, pasien kanker

\begin{abstract}
Cancer is one of the most cause of death in the world. In many cases, cancer patients didn't struggle alone for their treatment, but also accompanied by their family who became caregivers. There were some caregivers who found it difficult to realize quality of life and good psychological well-being. Therefore, this study aims to find out the relationship between quality of life and psychological well-being. This study used a quantitative approach with a type of correlational research. The research was conducted in Rumah Singgab Sehat Sejabtera and Rumah Singgah Kasib Bandung. The research subjects were 112 people using accidental sampling technique. The data was assessed with the Quality of Life Scale and Psychological Well-being Scale. The instrument's reliability coefficient was 0,893 $(a=0,893)$ on Quality of Life Scale and $0,938(a=0,938)$ on the Psychological Well-being Scale. Both were calculated using Cronbach's Alpha. Pearson product moment correlation technique was performed to analyze the data. The correlation coefficient was 0,619, the probability coefficient 0,000 $(p<0,01)$. The result of the research showed that quality of life was related to psychological well-being. Hence, higher quality of life level positively correlated to higher psychological well-being.
\end{abstract}

Keywords: quality of life, psychological well-being, caregiver, cancer patient

\section{Pendahuluan}

Penyakit kanker merupakan salah satu penyebab kematian utama di seluruh dunia. Pada tahun 2012, sekitar 8,2 juta kematian disebabkan oleh kanker. Kanker paru, hati, perut, kolorektal, dan kanker payudara adalah penyebab terbesar kematian akibat kanker tiap tahunnya. Secara nasional prevalensi penyakit kanker pada penduduk semua umur di Indonesia tahun 2013 sebesar 1,4\% atau diperkirakan sekitar 347.792. Provinsi Jawa Barat memiliki prevalensi yang cukup tinggi untuk penyakit kanker, yaitu sebesar $1 \%$ atau estimasi jumlah absolut sebesar 45.473 
jiwa (Pusadatin Kementerian Kesehatan RI, 2013).

Diagnosa kanker merupakan suatu kejadian dalam hidup yang dapat menyebabkan stress pada penderitanya. Stress tidak hanya terjadi pada pasien diagnosa kanker, tapi mempengaruhi aktivitas harian dari anggota keluarga, hubungan sosial, pekerjaan dan kualitas hidup. Hal-hal lain seperti stress juga dapat mempengaruhi anggota keluarga yang merasakan harus merawat anggota keluarga yang terdiagnosis kanker (Seven, 2014). Caregiver adalah seseorang baik perawat profesional ataupun anggota keluarga terdekat yang memberikan perawatan saat pasien sedang tidak berada di rumah sakit (Insan Medika, 2016). Menurut Bektas (2009), dengan adanya dukungan dari caregiver, maka akan mempengaruhi semangat dan kepatuhan pasien saat menerima pengobatan. Caregiver memiliki berbagai macam tanggung jawab seperti membuat janji dengan dokter, administrasi rumah sakit, dan memberikan perhatian pada pasien (Seven, 2014). Segala macam hal yang berhubungan dengan proses penyembuhan pasien dapat memengaruhi psychological well-being caregiver.

Psychological well-being seorang caregiver saat mereka merawat salah satu anggota keluarga yang mengalami penyakit kanker merupakan hal yang penting untuk diperhatikan. Hal ini perlu diperhatikan agar caregiver dapat merawat pasien dengan keadaan prima. Bila caregiver merasakan kecemasan, stress, dan depresi maka akan dapat mempengaruhi keadaan mental pasien.

Psychological well-being adalah keadaan seseorang yang dapat mengenali kemampuan menghadapi stress kehidupan sehari-hari, menjadi produktif, dan membuat kontribusi untuk komunitasnya sendiri. (WHO, 2005). Adanya peningkatan perhatian pada psychological well-being, diharapkan caregiver dapat meningkatkan kualitas hidupnya, memberikan dukungan sosial pada pasien penyakit kanker yang mengancam jiwa (Wakhidah, 2014).

Kualitas hidup adalah sebuah persepsi individu terhadap posisi mereka dalam kehidupan dengan konteks budaya dan sistem nilai dimana mereka tinggal dan hidup dalam hubungannya dengan tujuan hidup, harapan, standar, dan fokus hidup mereka (WHO, 2005). Kanker memengaruhi kualitas hidup caregiver pada berbagai dimensi kehidupan yaitu fisik (kelelahan, sakit, gangguan tidur, kehilangan kekuatan fisik, kehilangan nafsu makan, dan penurunan berat badan), psikologis (stress, kesulitan, kecemasan, kesepian, dan depresi), sosial (keuangan, isolasi, dan, pekerjaan), dan mengelola lingkungan (Obaidi, 2013).

Fasilitas kesehatan yang jauh mengharuskan caregiver untuk singgah di tempat lain agar dekat dengan fasilitas kesehatan seperti rumah sakit yang menerima pelayanan untuk pasien kanker. Seperti yang terjadi di kota Bandung terdapat yayasan yang dibuat untuk singgah bagi caregiver dan pasien. Adanya rumah singgah merupakan salah satu solusi untuk meringankan beban caregiver. Rumah singgah merupakan fasilitas penginapan yang digunakan oleh pasien dari daerah yang jauh dari rumah sakit yang kesulitan dalam penginapan di tengah kewajiban pengobatan (Kompas, 2018). Tujuan dari penelitian ini adalah untuk mengetahui dan memahami keterkaitan antara kualits hidup dan psychological well-being pada anggota keluarga yang menjadi cargiver kanker.

\section{Metode Penelitian}

Metode penelitian ini menggunakan pendekatan kuantitatif korelasional.

Penelitian ini dilaksanakan di Rumah Singgah Sehat Sejahtera dan Rumah Singgah Kasih di Kota Bandung. Penelitian dilaksanakan pada bulan Agustus sampai bulan Oktober 2019 dan pengambilan data pada tanggal 30 September - 14 Oktober 2019. 
Subjek penelitian merupakan anggota keluarga yang menjadi caregiver pasien kanker dengan teknik accidental sampling. Subjek penelitian berjumlah 112 orang.

Subjek diberikan kuesioner yang mengukur kualitas hidup dan psychological well-being.

Teknik pengumpulan data menggunakan kuesioner. Instrumen yang digunakan penelitian adalah Skala Kualitas Hidup oleh WHQOL-BREF dan Weitzner (1999) yang terdiri dari kesehatan fisik, psikologis, hubungan sosial, dan lingkungan. Skala Psychological Well-being disusun berdasarkan dimensi yang dikemukakan oleh Ryff (1989) yang terdiri dari penerimaan diri, hubungan positif dengan orang lain, kemnadirian, penguasaan lingkungan, tujuan hidup, dan pengembangan pribadi.

Data dianalisis secara deskriptif dengan membuat kategori hasil skor kualitas hidup dan psychological well-being menjadi 5 kategori. Dengan berpedoman pada skor rata-rata dan standar deviasi, data dikelompokkan menjadi: sangat rendah, rendah, sedang, tinggi dan sangat tinggi. Analisis uji normalitas KormogorovSmirnov dan uji linieritas dilakukan untuk memenuhi asumsi analisis korelasi. Teknik analisis korelasi product moment digunakan untuk menguji hubungan antara variabel bebas dan variabel tergantung. Analisis data dilakukan dengan dilakukan dengan bantuan SPSS Statistic for windows.

\section{Hasil Penelitian}

Subjek dalam penelitian ini adalah anggota keluarga yang sedang mendampingi pasien saat sedang melakukan pengobatan atau bisa disebut sebagai caregiver. Terdapat 112 anggota keluarga yang menjadi caregiver sebagai sampel dalam penelitian ini dengan deskripsi subjek sebagaimana tampak pada tabel 1.
Tabel 1. Deskripsi Jenis Kelamin Subjek

\begin{tabular}{lll}
\hline $\begin{array}{l}\text { Jenis } \\
\text { Kelamin }\end{array}$ & Jumlah & Persentase \\
\hline Laki - laki & 50 & $44,6 \%$ \\
Perempuan & 62 & $55,4 \%$ \\
\hline Total & $\mathbf{1 1 2}$ & $\mathbf{1 0 0 \%}$ \\
\hline
\end{tabular}

Pada tabel 2. Menunjukkan rata-rata responden berada pada rentang usia $41-50$ tahun. Responden paling sedikit berada pada rentang usia $20-30$ tahun.

Tabel 2. Deskripsi Rentang Usia Subjek

\begin{tabular}{cll}
\hline Rentang Usia & Jumlah & Persentase \\
\hline $20-30$ & 15 & $13,3 \%$ \\
$31-40$ & 29 & $25,9 \%$ \\
$41-50$ & 44 & $39,4 \%$ \\
$51-60$ & 24 & $21,4 \%$ \\
\hline Total & $\mathbf{1 1 2}$ & $\mathbf{1 0 0} \%$ \\
\hline
\end{tabular}

Pada tabel 3. Terlihat bahwa sebagian besar subjek memiliki hubungan keluarga sebagai suami/ istri. Responden paling sedikit adalah hubungan dengan pasien sebagai anak.

Tabel 3. Deskripsi Hubungan dengan Pasien

\begin{tabular}{lll}
$\begin{array}{l}\text { Hubungan dengan } \\
\text { Pasien }\end{array}$ & Jumlah & Persentase \\
\hline Suami/ Istri & 63 & $56,2 \%$ \\
Orang Tua & 27 & $24,1 \%$ \\
Anak & 5 & $4,5 \%$ \\
$\begin{array}{l}\text { Anggota keluarga } \\
\quad \text { lain }\end{array}$ & 17 & $15,2 \%$ \\
\hline Total & $\mathbf{1 1 2}$ & $\mathbf{1 0 0} \%$ \\
\hline
\end{tabular}

Tabel 4. Menunjukkan bahwa frekuensi terbanyak terdapat pada kategori tinggi sebanyak 51 subjek $(50,9 \%)$. Frekuensi terendah pada kategori sangat rendah yaitu 0 subjek $(0 \%)$. Hal ini berarti bahwa mayoritas responden merasa bahwa kualitas hidup yang dimiliki berada pada tingkat tinggi dan hanya sedikit responden 
yang merasa bahwa kualitas hidup yang dimiliki rendah.

Tabel 4. Distribusi Frekuensi Kualitas Hidup

\begin{tabular}{lll}
\hline Kategori & $\mathrm{F}$ & $(\%)$ \\
\hline Sangat Rendah & 0 & $0 \%$ \\
Rendah & 16 & $14,3 \%$ \\
Sedang & 31 & $27,7 \%$ \\
Tinggi & 57 & $50,9 \%$ \\
Sangat Tinggi & 8 & $7,1 \%$ \\
\hline
\end{tabular}

Tabel 5. Menunjukkan bahwa frekuensi terbanyak terdapat pada kategori tinggi sebanyak 45 subjek (40,2\%). Frekuensi terendah pada kategori sangat rendah dan rendah yaitu 0 subjek $(0 \%)$. Hal ini berarti bahwa mayoritas responden merasa pada tingkat psychological well-being yang tinggi dan tidak ada responden yang merasa bahwa psychological well-being yang dimilikinya rendah.

Tabel 5. Distribusi Frekuensi Psychological

\begin{tabular}{lll} 
Well-being & & \\
\hline Kategori & $\mathrm{F}$ & $(\%)$ \\
\hline Sangat Rendah & 0 & $0 \%$ \\
Rendah & 0 & $0 \%$ \\
Sedang & 32 & $28,6 \%$ \\
Tinggi & 45 & $40,2 \%$ \\
Sangat Tinggi & 35 & $31,2 \%$ \\
\hline
\end{tabular}

Berdasarkan Tabel 6, dapat diketahui bahwa koefisien korelasi untuk variabel kualitas hidup dan psychological well-being adalah 0,619 dengan taraf siginifikansi (p) $=0,000$. Perhitungan ini dilakukan pada taraf siginifikansi $\mathrm{p}<0,01$ dan menggunakan uji dua ekor (2-tailed). Hal hasil terssebut menunjukkan bahwa ada hubungan yang positif antara kualitas hidup dan psychological well-being pada anggota keluarga yang menjadi caregiver. Hasil analisis data yang diperoleh membuktikan bahwa hipotesis penelitian ini diterima. Artinya, semakin tinggi tingkat kualitas hidup akan diikuti dengan tingginya tingkat psychological wellbeing pada anggota keluarga yang menjadi caregiver.

Tabel 6. Hasil Uji Hipotesis

\begin{tabular}{llll}
\hline \multicolumn{2}{c}{ Correlations } & $\begin{array}{c}\text { Kualitas } \\
\text { Hidup }\end{array}$ & PWB \\
\hline Kualitas & Pearson & 1 & .619 \\
Hidup & Correlation & & $* *$ \\
& Sig. (2-tailed) & & .000 \\
& N & 112 & 112 \\
PWB & Pearson & $.619^{* *}$ & 1 \\
& Correlation & & \\
& Sig. (2-tailed) & .000 & \\
& N & 112 & 112 \\
\hline \multirow{3}{*}{ Berdasarkan hasil analisis pada tabel }
\end{tabular}

Tabel 7. Hasil Uji Korelasi Kualitas Hidup dan Psychological Well-being berdasarkan nilai r hitung.

\begin{tabular}{lllllll}
\hline \multicolumn{6}{c}{ Correlations } \\
\hline Variabel 1: & \multicolumn{5}{c}{ Variabel 2: Psychological Well-Being } \\
\cline { 2 - 7 } Hidup & $\begin{array}{c}\text { Penerimaan } \\
\text { Diri }\end{array}$ & $\begin{array}{c}\text { Hubungan } \\
\text { Positif } \\
\text { dengan } \\
\text { Orang } \\
\text { Lain }\end{array}$ & Kemandirian & $\begin{array}{c}\text { Penguasaan } \\
\text { Lingkungan }\end{array}$ & $\begin{array}{c}\text { Tujuan } \\
\text { Hidup }\end{array}$ & $\begin{array}{c}\text { Pengembangan } \\
\text { Pribadi }\end{array}$ \\
\hline $\begin{array}{c}\text { Kesehatan } \\
\text { Fisik }\end{array}$ & 0,223 & 0,112 & 0,363 & 0,042 & $-0,272$ & 0,200 \\
$\begin{array}{l}\text { Psiklogis } \\
\text { Hubungan }\end{array}$ & 0,518 & 0,522 & $-0,252$ & 0,423 & $-0,764$ & 0,094 \\
Sosial & 0,568 & 0,383 & $-0,313$ & $-0,473$ & 0,713 & $-0,526$ \\
Lingkungan & 0,087 & 0,751 & $-0,516$ & 0,255 & $-0,952$ & 0,998 \\
\hline
\end{tabular}


7, berdasarkan jumlah responden 112 sehingga nilai $\mathrm{r}$ tabel $=0,195$. Aspek kesehatan fisik memiliki korelasi positif dengan aspek penerimaan diri, kemandirian, dan pengembangan pribadi. Aspek psikologis memliki korelasi positif dengan aspek penerimaan diri, hubungan positif dengan orang lain, dan penguasaan lingkungan. Aspek hubungan sosial memiliki korelasi positif dengan aspek penerimaan diri, hubungan positif dengan orang lain, dan tujuan hidup. Aspek lingkungan memiliki korelasi positif dengan aspek hubungan positif dengan orang lain, penguasaan lingkungan, dan pengembangan pribadi.

\section{Pembahasan}

Hasil penelitian menunjukkan bahwa dari 112 anggota keluarga yang menjadi caregiver di rumah singgah 31 orang memiliki tingkat kualitas hidup yang sedang dan 57 orang memiliki tingkat kualitas hidup yang tinggi. Dengan demikian dapat disimpulkan bahwa tingkat kualitas hidup pada anggota keluarga yang menjadi caregiver mayoritas pada kategori tinggi. Cargiver yang memiliki tingkat kualitas hidup yang tinggi mampu memenuhi aspek kualitas hidup yaitu kesehatan fisik, psikologis, hubungan sosial, dan lingkungan.

Dalam penelitian ini, rerata skor yang didapatkan adalah 70 . Hal ini berarti sejalan dengan penelitian yang dilakukan oleh Rahmatiah, Kadar, dan Erika (2018) bahwa adanya tingkat kualitas hidup caregiver ada pada tingkat tinggi. Tingkat rerata kualitas hidup caregiver sebesar 71,22.

Hasil penelitian menunjukkan bahwa dari 112 anggota keluarga yang menjadi caregiver di rumah singgah sebanyak 32 orang memiliki tingkat psychological wellbeing yang sedang dan 45 orang memiliki tingkat psychological well-being tinggi.

Dengan demikian dapat disimpulkan bahwa tingkat psychological well-being pada anggota keluarga yang menjadi caregiver mayoritas pada kategori tinggi.

Menurut penelitian yang dilakukan Qudwatunnisa (2018) di Bandung, hasil yang didapatkan tingkat psychological wellbeing pada kategori sedang. Psychological wellbeing memiliki enam dimensi utama yaitu kemandirian, penguasaan lingkungan, pertumbuhan pribadi, hubungan yang positif dengan orang lain, memiliki tujuan hidup, dan penerimaan diri (Ryff, 1989). Secara keseluruhan responden dikatakan cukup mampu mengambil keputusan secara mandiri maupun mengevaluasi diri dengan standar pribadi, cukup mampu mengelola dan mengatur kondisi lingkungan yang sesuai kebutuhan dirinya, cukup mampu mengembangkan potensi yang ada dalam dirinya secara berkelanjutan, cukup memiliki perasaan yang hangat dan saling percaya dengan orang lain, cukup memiliki keyakinan untuk mencapai tujuan hidupnya, dan cukup mampu menerima keadaan dirinya dari segala aspek termasuk yang baik dan buruk dalam dirinya serta mampu menerima keadaan dirinya dimasa lalu. Hasil penelitian ini menunjukkan bahwa tidak selamanya anggota keluarga yang menjadi caregiver memiliki tingkat psychological well-being yang rendah dikarenakan stress dan beban emosional yang didapat selama masa perawatan. Penelitian ini sejalan dengan Qudwatunnisa (2018) yang menunjukkan bahwa caregiver dapat memiliki tingkat psychological well-being yang cukup baik.

Berdasarkan hasil penelitian yang sudah dilakukan dihasilkan bahwa terdapat hubungan positif antara kualitas hidup dan psychological well-being pada anggota keluarga yang menjadi caregiver. Hal ini ditunjukkan dengan hasil analisis data yang diperoleh nilai koefisien korelasi sebesar 0,619 dengan $\mathrm{p}<0,01$.

Kondisi fisik merupakan hal yang penting dalam memengaruhi psychological wellbeing. Aspek kesehatan fisik memiliki korelasi positif dengan aspek penerimaan 
diri, kemandirian, dan pengembangan pribadi. Seiring dengan berjalannya waktu, caregiver mampu melakukan penyesuaian pada kegiatan sehari-hari. Dengan keadaan fisik yang baik, maka penerimaan diri, kemandirian, dan pengembangan pribadi dapat dicapai dengan baik oleh cargiver. Hal ini sesuai dengan penelitian yang dilakukan Hadiputra (2013) seorang caregiver memiliki beban yang berat, namun harus mampu bersikap positif terhadap dirinya dan lingkungan, serta tetap menjalani kehidupannya dengan mengatasi segala tantangan. Selain itu, caregiver juga harus mempunyai kemandirian dalam membuat keputusan dalam bertindak, seperti membuat keputusan untuk menentukan pelayanan seperti apa yang harus diberikan pada pasien kanker. Hal ini sesuai dengan penelitian yang dilakukan Wakhidah (2014) Caregiver masih mampu mengambil keputusan sendiri secara mandiri untuk hal-hal tertentu.

Pada penelitian ini, aspek psikologis memiliki skor yang cukup tinggi dan indikator spiritualitas memiliki korelasi signifikan dengan aspek psychological wellbeing yaitu, penerimaan diri, hubungan yang positif dengan orang lain, dan penguasaan lingkungan. Caregiver yang memiliki hubungan positif yang baik dengan orang lain memiliki dampak positif untuk meningkatkan kualitas hidup. Hal ini sesuai dengan penelitian yang dilakukan Ownsorth, Henderson, dan Chambers di Australia (2010) yang menyatakan bahwa hubungan sosial yang baik akan meningkatkan psychological well-being. Selain itu, aspek psikologis memiliki skor yang cukup tinggi pada indikator spiritualitas. Spiritualitas berpengaruh terhadap meningkatnya psychological well-being. Caregiver percaya bahwa apa yang diberikan oleh tuhan adalah sebuah ujian yang harus dihadapi. Hal ini berarti sesuai dengan penelitian Wakhidah (2014) yang menyatakan bahwa spiritualitas menjadi hal yang signifikan untuk memengaruhi akan kekuatan dari masingmasing caregiver.
Selanjutnya aspek hubungan sosial memiliki korelasi positif dengan aspek penerimaan diri, hubungan positif dengan orang lain, dan tujuan hidup. Caregiver dengan hubungan sosial yang baik dapat mengaktualisasikan dirinya, menerima dirinya sendiri, dan memiliki kepercayaan diri. Biasanya mereka juga tergabung dalam komunitas yang ada pada masyarakat. Penelitian yang dilakukan Wakhidah (2015) yang menyatakan memang sulit awalnya untuk menerima anggota keluarga yang menderita penyakit kanker, namun hal iru dapat diatasi dengan seiring berjalannya waktu. Selanjutnya aspek tujuan hidup sama seperti penelitian yang dilakukan Safitri, Binahayati, dan Taftazani di Jakarta (2016) yang menyatakan caregiver yang memiliki anggota keluarga yang menjadi pasien kanker dapat memiliki dampak kehilangan motivasi dan tujuan hidup. Maka dari itu hubungan sosial yang bisa berupa dukungan sosial dapat diberikan agar caregiver tidak kehilangan motivasi dan tujuan hidup. Selain itu, hal ini juga sejalan dengan penelitian yang dilakukan oleh Vania (2014) yang menyatakan adanya pengaruh dukungan hubungan sosial terhadap psychological wellbeing berkaitan dengan hubungan positif dengan orang lain, yang menunjukkan bahwa psychological well-being diperngaruhi oleh kontak sosial dan hubungan interpersonal. Aspek lingkungan memiliki korelasi positif dengan aspek hubungan positif dengan orang lain, penguasaan lingkungan, dan pengembangan pribadi. Caregiver dengan lingkungan yang baik dapat meningkatkan hubungan sosial dengan orang lain secara positif, mampu mencari informasi untuk perawatan bagi pasien kanker, dan melakukan pengembangan diri. Penelitian yang dilakukan Safitri, Binahayati, dan Taftazani di Jakarta (2016) dimana caregiver mendapatkan dukungan informasi yang berarti memberi solusi pada suatu masalah. Caregiver memiliki hubungan yang baik dengan perawat dan dokter di rumah sakit, sehingga infomasi yang didapatkan berasal 
dari sumber yang tepat. Dengan informasi yang tepat, maka akan meringankan beban yang dirasakan oleh caregiver. Penelitian yang dilakukan Cormio, Romito, Viscanti, Turaccio, Lorusso dan Mattioli (2014) di Itali menunjukkan bahwa caregiver memiliki skor yang baik pada aspek psychological wellbeing yaitu pengembangan diri.

Hasil penelitian ini juga menunjukkan ketika kualitas hidup yang dimiliki oleh caregiver ada pada tingkat tinggi maka psychological well-being juga ada pada tingkat tinggi. Hal ini berarti bahwa tingkat kualitas hidup mempengaruhi psychological well-being secara signifikan. Penelitian yang dilakukan oleh Yu Lee, PaoYen Li, Chih Yen Chien, Fu Minfang Dan Liang Jen Wang di Taiwan (2018). Hasil penelitian ini menyatakan bahwa tingkat psychological wellbeing yang mengalami penurunan diikuti dengan tingkat kualitas hidup yang menurun. Hal ini disebabkan karena adanya beban yang dialami oleh caregiver saat melakukan perawatan. Namun pada penelitian ini, caregiver mampu memenuhi aspek-aspek yang ada pada kualitas hidup dan psychological well-being sehingga caregiver berada pada tingkat kualitas hidup dan psychological well-being yang baik. Pasien dan caregiver yang berada di rumah singgah dapat menikmati fasilitas secara gratis. Fasilitas penunjang yang diberikan oleh rumah singgah dapat membantu meningkatkan kualitas hidup dan psychological well-being.

Pada penelitian ini dapat ditemukan bahwa tingkat kualitas hidup dan psychological well-being mayoritas pada tingkat tinggi. Hal ini disebabkan karena ada beberapa fasilitas penunjang pada rumah singgah yang dapat digunakan oleh pasien dan caregiver. Berdasarkan uraian di atas, dapat disimpulkan bahwa ada perbedaan tingkat kualitas hidup dan psychological wellbeing di tiap tempat yang berbeda.

\section{Simpulan dan Saran}

Terdapat hubungan positif antara kualitas hidup dan psychological well-being pada anggota keluarga yang menjadi caregiver di Kota Bandung. Hal ini berarti apabila tingkat kualitas hidup tinggi maka tingkat psychological well-being akan tinggi, namun sebaliknya bila tingkat kualitas hidup rendah maka tingkat psychological wellbeing juga rendah.

Penelitian selanjutnya terkait variabel kualitas hidup maupun psychological wellbeing diharapkan memiliki subjek yang lebih banyak dan wilayah generalisasinya lebih luas tidak hanya di Kota Bandung. Selain itu, penelitian ini sebaiknya dilakukan secara kualitatif agar hasil yang didapatkan lebih mendalam dan detail. Instrumen yang digunakan harus menggunakan bahasa dan instruksi yang lebih dipahami oleh responden penelitian. Masyarakat juga harus lebih memahami bahwa keadaan kualitas hidup dan psychological well-being merupakan hal yang penting untuk diperhatikan. Dengan demikian masyarakat tidak hanya fokus pada pasien, namun dapat memberikan dukungan kepada orang yang menjadi caregiver.

\section{Daftar Pustaka}

Pusadatin Kementrian Kesehatan RI. (2013). Pusat data dan informasi kementrian kesehatan RI. Jakarta: Pusat Data dan Informasi.

Seven, Memnun, Sakine Yilmaz, Eda Sahin, \& Aygul Akyuz. (2014). Evaluation of the quality of life of caregivers in gynaecological cancer patients. New York: Jurnal Canc Educ. No. 29:325 - 332 .

Insan Medika. (2018). Apakah caregiver itu?. Jakarta: PT. Insan Medika Persada. Diakses 18 Januari 2019 melalui https://insanmedika.co.id/article/ap ak ah-caregiver-itu.

Bektas, H.A \& Ozer Z.C. (2009). Reliability and validity of the caregiver quality of life index-cancer (CQOLC) scale in Turkish 
cancer caregivers. Turki: Journal of Clinical Nursing Vol. 18 No. 21: 30033012.

Wakhidah. (2014). Pychological well-being pada caregiver penyakit terminal di kota malang. Skripsi. Malang: Universitas Islam Negeri Malang.

World Health Organization. (2005). Promoting mental bealth. Geneva: WHO Press.

Obaidi, J. G., \& Al-Atiyyat, N. M. (2013). Quality of life among primary caregivers of women with breast cancer: $A$ review. Shiraz: Middle East Journal of Cancer. No. 2: 45-49.

Wicaksono, Bhakti Satrio. (10 Oktober 2018). Rumah singgah, opsi bagi pasien luar kota yang perlu menginap. Diakses $23 \quad$ Oktober 2019. https://sains.kompas.com/read/201 8/ 10/10/203600423/rumahsinggahopsi-bagi-pasien-luar-kotayangperlu-menginap?page $=$ all

WHOQOL-Bref. (1996). Introduction, administration, scoring, and generic version of assessment. Geneva: World Health Organization.

Weitzner, M.A, Jacobsen P.B., H. Wagner \& J. Friedland. (1999). The caregiver quality of life index-cancer (CQOLC) scale: development and validation of an instrument to measure quality of life of the family caregiver of patients cancer. Florida: Journal Quality of Life Vol. 8: 55 - 63.

Ryff, C. D. (1989). Happiness is everything, or is it? Explorations on the meaning of psychological wellbeing. Washington: Journal of Personality and Social Psychology. No. 57: 1069-1081.

Rahmatiah, Kusrini Kadar \& Kadek Ayu Erika. (2018). Tingkat keterlibatan dan kualitas bidup family caregivers dalam merawat pasien kanker di RSUD Wabidin Sudirobusodo Makasar. Makasar: Jurnal Penelitian dan
Pemikiran Ilmiah Keperawatan. Vol. 4 No.2: 94 - 99.

Quwadtunnisa, Fatimah F, Ahmad Yamin, \& Efri Widianti. (2018). Gambaran kesejabteraan psikologis pada family caregiver orang dengan skizofrenia di instalasi rawat jalan ghraatmma bandung. Bandung: Nurse Line Journal. No. 1: $20-29$.

Hadiputra, M.Qzaky. (2017). Upaya meningkatkan kesejabteraan psikologis family caregiver di yayasan Alzheimer Indonesia. Skripsi. Jakarta: UIN.

Onsworth, Tamara, Laura Henderson, \& Suzzane K. Chambers. (2010). Social support buffers the impact of functional impairments on caregiver psychological wellbeing in the context of brain tumor and other cancers. Australia: Journal Psychooncology No. 19: 1116 1122.

Safitri, Yana, Binahayati, \& Budi M. Taftazani. (2017). Dukungan sosial terhadap orangtua anak penderita kanker di yayasan komunitas Taufan Jakarta Timur. Bandung: Unversitas Padjajaran Jurnal Penelitian dan Pengabdian Kepada Masyarakat Vol. 4 No.2: 129 - 389.

Vania, Ignatia Widyanita \& Karika Sari Dewi. (2014). Hubungan antara dukungan sosial dengan psychological well-being caregiver penderita gangguan skizofrenia. Semarang, Universitas Dipenogoro. Jurnal Empati No 4: $266-278$.

Cormio, Calaudia, Francesca Romito, dkk. (2014). Psychological well-being and posttraumatic growth caregivers of cancer patietnts. Turin: Frontiers in Pyschology. No. 5: $1-8$.

Lee, Yu, Pao-Yen Lin dkk. (2018). A comparison of psychological wellbeing and quality of llife between spouse and nonspouse caregivers in patients with head and 
nesk cancer: A 6-months follow-up study.

Kaohsiung: Dove press journal

Neuropsychiatric and treatment

No.14, 1697 - 1704. 